\title{
Studying the relationships of various agronomic traits in maize using correlation analysis
}

\author{
Seyed Mohammad Nasir MOUSAVI - Karamchand BRAMDEO - Safwan MOHAMMED \\ - János NAGY \\ University of Debrecen Faculty of Agricultural and Food Sciences and Environmental Management, Institute of \\ Land Use, Technology and Regional Development. Email: Nasir@agr.unideb.hu.
}

Keywords: Regression model, Correlation, Maize, Traits

\section{Introduction}

Maize (Zea mays L.) has a prominent place in global agriculture and considered to be as one of the major cereal in the world. Grain yield in corn is a complex character that is controlled by many factors. Selection of desirable genotypes should be based on grain yield and other functional characteristics that affect grain yield. In order to develop highyield promising genotypes, it is essential to identify the relationships between different traits, especially grain yield (Mohammadia, 2003). Correlation analysis is usually used to measure the relative amount of the influence of each of these independent variables on an associated variable, such as grain yield. The proper knowledge of this relationship between grain yield and its characteristics can significantly improve the efficiency of breeding programs by using appropriate selection indicators (Fazelifard, 2014).

Multiple regression is the extension of a simple regression (bivariate). The result of multiple regressions is the development of an equation of regression (the most appropriate line) between the dependent variable and several independent variables. The goal of multiple regressions is to enable a researcher to assess the relationship between a dependent variable and several independent (predictor) variables (Hocking ,1976; SAS Institute Inc ,1989). The main goal for this study evaluation of some trait's agronomic maize on yield in Hungary.

\section{Materials and Methods}

Samples were taken from location in Debrecen. Our experiment had in four replications in six nitrogen fertilizer level. The measured traits in maize included Stem diameter (SD), outer ear diameter (OD), number of nodes (NN), weight of ear(WE), weight of cob (WC), number seeds in each row (NSR), number seeds in each column (NSC), length of ear (LE), weight all seed in each ear (WSE), Number of seed in each ear (NSE), weight of plant fresh in hectare (WFP), weight of dry plant in hectare (WDP) and hybrids this experiment are DKC4670 and ES Faraday 340. Finally, all data and results had been driven to Genstat software for statistical analysis.

\section{Results and discussion:}

Correlation between traits showed that weight of ear with weight of cob, weight of seed in each ear with weight of ear and weight of cob and weight of fresh plant in hectare with stem diameter, outer ear diameter, weight of cob and number of seeds in row has positive correlation together. Also, there is negative correlation between number of seeds on row with length of ear in this study (table 1). 
A regression model was set up in this study. The result of the regression shows that the regression model is significant in one percent level of this study. Also, dependent variable (traits measurement) is 97.33 percent in this study. Consequently, we can use regression model for this study (Table 2).

Table 1: Correlation between traits in two hybrids in maize

\begin{tabular}{|c|c|c|c|c|c|c|c|c|c|c|c|c|c|}
\hline & SD & OD & $\mathrm{NN}$ & WE & WC & NSR & NSC & LE & WSE & NSE & 1000 seeds & WFP & WDP \\
\hline SD & 1.000 & $0.353^{* *}$ & $0.366^{* *}$ & 0.103 & 0.171 & $0.217^{*}$ & $0.201^{*}$ & 0.167 & 0.103 & 0.119 & 0.147 & $0.389^{* *}$ & $0.387^{* * *}$ \\
\hline OD & & 1.000 & $0.306^{* *}$ & 0.147 & $0.252^{*}$ & $0.425^{* *}$ & 0.102 & $0.297^{* *}$ & 0.146 & 0.186 & 0.160 & $0.452^{* *}$ & $0.446^{* *}$ \\
\hline $\mathrm{NN}$ & & & 1.000 & 0.167 & $0.207^{*}$ & 0.125 & 0.036 & 0.050 & 0.164 & -0.003 & 0.181 & 0.191 & $0.213^{*}$ \\
\hline WE & & & & 1.000 & $0.786^{* *}$ & $0.212^{*}$ & 0.088 & 0.057 & $0.967^{* *}$ & $0.203^{\circ}$ & $0.280^{* *}$ & 0.105 & 0.126 \\
\hline WC & & & & & 1.000 & $0.227^{*}$ & 0.113 & 0.094 & $0.766^{* *}$ & 0.161 & $0.251^{*}$ & $0.204^{*}$ & $0.225^{*}$ \\
\hline NSR & & & & & & 1.000 & -0.098 & $-0.624^{* *}$ & $0.218^{*}$ & $0.232^{\circ}$ & 0.089 & $0.290^{* *}$ & $0.270^{* *}$ \\
\hline NSC & & & & & & & 1.000 & $0.327^{* *}$ & 0.091 & $0.437^{\circ *}$ & 0.069 & 0.146 & 0.127 \\
\hline LE & & & & & & & & 1.000 & 0.054 & $0.211^{*}$ & -0.025 & 0.107 & 0.139 \\
\hline WSE & & & & & & & & & 1.000 & $0.207^{\circ}$ & $0.290^{* *}$ & 0.101 & 0.122 \\
\hline NSE & & & & & & & & & & 1.000 & 0.012 & 0.141 & 0.134 \\
\hline 1000 seeds & & & & & & & & & & & 1.000 & 0.123 & 0.102 \\
\hline WFP & & & & & & & & & & & & 1.000 & $0.883^{* *}$ \\
\hline WDP & & & & & & & & & & & & & 1.000 \\
\hline
\end{tabular}

Stem diameter (SD), outer ear diameter (OD), number of nodes (NN), weight of ear(WE), weight of cob (WC), number seeds in each row (NSR), number seeds in each column (NSC), length of ear (LE), weight all seed in each ear (WSE), Number of seed in each ear (NSE), weight of fresh plant in hectare (WFP), weight of dry plant in hectare (WDP).

Table 2: Regression between traits in two hybrids in maize

\begin{tabular}{|c|c|c|c|c|c|}
\hline Source & DF & SS & MS & F & $\mathrm{R}^{2}$ \\
\hline Regression & 10 & 13.8832 & 1.38832 & $806.61 * *$ & $97.33 \%$ \\
\hline Residual Error & 36 & 0.062 & 0.00172 & & \\
\hline Total & 46 & 13.9452 & & & \\
\hline
\end{tabular}

\section{Conclusions}

Maize is an important cereal in the world. This study showed that many traits have effect on the fresh weight of the maize plant with stem diameter, outer ear diameter, weight of cob and number of seeds in row having the most effect for yield. Consequently, in order to obtain the highest yield of these hybrids, one needs to focus on these traits.

\section{Acknowledgement}

The research was financed by GINOP-2.2.1-15-2016-00001 project and by the Higher Education Institutional Excellence Programme (20428-3/2018/FEKUTSTRAT) of the Ministry of Human Capacities in Hungary, within the framework of the 4th thematic programme of the University of Debrecen.

\section{References}

Fazelifard, F., Mirshekari, B., Amirnia, R., (2014): Multiple regression analysis for studied traits in intercropping of popcorn and cowpea International Journal of Biosciences.International Journal of Biosciences. Vol. 4, No. 4, p. 116-120. http://dx.doi.org/10.12692/ijb/4.4.116-120.

Hocking,RR. (1976): The analysis and selection of variables in linear regression, iometrics. Agriculture Ecosystems and Environment 102, 279-297. http://dx.doi.org/10.1198/jcgs.2009.06164

Mohammadia, S.A., Prasanna, B. M., Singh, N. N. (2003): Sequential path model for determining interrelationship among grain yield and related characters in maize. Crop Science., 43: 1690-1697. doi:10.2135/cropsci2003.1690.

SAS Institute Inc (1989): SAS/STAT User's Guide, Version 6, Fourth Edition, Volume 2, Cary, NC: SAS Institute Inc. 